Sofía ORAZI, PhD Candidate

E-mail:sofiaorazi@iiess-conicet.gob.ar

Instituto de Investigaciones Económicas y Sociales del Sur

(UNS - CONICET); Universidad Nacional del Sur

Departamento de Economía, Bahía Blanca, Argentina

Lisana Belén MARTINEZ, PhD

E-mail: lbmartinez@iiess-conicet.gob.ar

Instituto de Investigaciones Económicas y Sociales del Sur

(UNS - CONICET) Universidad Nacional del Sur

Departamento de Economía; Universidad Provincial del Sudoeste

Bahía Blanca, Argentina

Professor Hernán Pedro VIGIER, PhD

E-mail: hvigier@upso.edu.ar

Universidad Provincial del Sudoeste (UPSO-CEDETS)

Universidad Nacional del Sur; Centro de Investigaciones Científicas de la Provincia de Buenos Aires (CIC). Bahía Blanca, Argentina

Maria Belén GUERCIO, PhD

E-mail: mbguercio@iiess-conicet.gob.ar

Instituto de Investigaciones Económicas y Sociales del Sur

(UNS - CONICET); Universidad Provincial del Sudoeste

Bahía Blanca, Argentina

\title{
A REGIONAL KOHONEN MAP OF FINANCIAL INCLUSION AND RELATED MACROECONOMIC VARIABLES
}

Abstract. Financial inclusion increases savings, promotes investment and the expansion of the domestic market, and consequently favors economic growth. In this work, the evolution of a set of indicators of financial inclusion is analyzed simultaneously with a group of macroeconomic variables. The methodology applied is a particular type of neural network, called Self Organizing Maps (SOM). The data is for the years 2011, 2014 and 2017 including data from 37 countries belonging to three great regions: Latin America, Europe and Asia.

The results show that there are five groups of countries with similar characteristics of financial inclusion and macroeconomic indicators, nonetheless, there are countries that move through different groups over the years studied. Also, there is evidence that the macroeconomic variables are related with the levels of financial inclusion; those countries with great GDP per capita, higher education and employment, present better levels of financial inclusion.

Keywords: Financial Inclusion; Self-Organizing Maps; Latin America; Europe; Asian Tigers.

JEL Classification: G51 - 016 - C45 - N20 


\section{Introduction}

Financial inclusion refers to the process of ensuring access to appropriate and affordable financial products and services needed by all individuals and enterprises in general. It intends to facilitate the availability, accessibility and usage of formal financial services to those sectors not reached by traditional finance markets, due to economic, cultural or educational constrains (Demirguc-Kunt and Klapper, 2013; Marconi, 2014).

The typical definition of financial inclusion is the proportion of households and firms that use financial services (World Bank, 2014), and its simplest meaning is measured through access to a bank account, since the banking services are the most widespread and accessible sector, which makes possible the comparison between regions and countries (Martínez Pería, 2014). Also, access to a bank account allows saving money, making and receiving payments, and obtaining other services such as insurance and credit (Singh, 2017).

There is consensus that many potential benefits emerge from promoting formal financial institutions. A growing body of research reveals that financial inclusion fosters inclusive economic development, channeling savings and productive investments thorough a large portion of population and enterprises, providing employment and income and improving the livelihoods of the poorest (Sahay et. al., 2015).

The alternatives financial sources for people excluded from the banking system are generally more expensive, insufficient or unsafe (Collins et al., 2009). For these reasons, financial inclusion aims to create tools for those excluded and vulnerable sectors in order to improve their economic activity and financial stability and safety (De Olloqui et al., 2015; Demirguc-Kunt and Klapper, 2013).

This topic becomes relevant as a public policy option that leads to financial development, as part of socio-economic development, contributing to the reduction of poverty, acquiring assets, investing and improving the level of income (Cihak et al., 2012; De Olloqui et al, 2015). Some international groups support the local efforts to boost financial inclusion, like the World Bank, the International Monetary Fund, the United Nations, and the Alliance for Financial Inclusion.

In this context, arise the importance of studying the evolution of financial inclusion and in this work is analyzed simultaneously with a group of economic variables. The years of study are 2011, 2014 and 2017, which correspond to the data selected in the Global Findex Database, which involve the variables related with the financial inclusion.

The macroeconomic variables included are extracted from the World Bank and the International Monetary Fund databases. The groups of countries under study are: 9 Latin American, 19 European and 9 Asian tigers.

The methodology applied is a particular type of artificial neural network, called Kohonen Self Organizing Maps (SOM) which allows us to analyze all the variables at the same time, and gives a dimensional map identifying the closest elements, with similar characteristics. 
A Regional Kohonen Map of Financial Inclusion and Related Macroeconomic Variables

There are many objectives pursued in the present paper. The first of them is focused to detect if financial inclusion progression is in concordance with the evolution of the macroeconomic variables for the countries considered in the sample. The second one is based to detect the evolution of those countries that changed groups over the years, proving an improvement or a decline in their situation. The third objective is to observe the resulting division of countries in comparison with their own geographic region belonging, in order to detect new groups of countries with similar points of contact.

The remaining of the paper is organized as follows. Section 2 contains brief Literature review considering the linkage of financial inclusion and macroeconomic variables. Section 3 describes the Self Organizing Kohonen maps as an innovative methodology applied. Section 4 describes de data used for the study and the variables considered. Section 5, presents the results obtained and finally, section 5 shows the main conclusions.

\section{Brief Literature Review}

The great importance of the financial inclusion over the real economies is a relative new area of study of many institutions. Some works analyze the link between the financial inclusion and the improvement of economic variables.

Ezenwakwelu (2018) studied the effect of financial inclusion on economic growth, unemployment and human development in Nigeria for the period 2007 to 2015. He found that there are significant relationships between financial inclusion, unemployment and human development, although there was not enough significant relationship between financial inclusion and gross domestic product.

Likewise, Bruhn and Love (2014) studied the effects of financial inclusion in regions that were underprovided financial services in Mexico. These authors detected that the expansion of financial institutions, especially focused on the population excluded from the financial system, of middle- and low-income, has a positive impact on their access to the labor market, the development of entrepreneurships and the increase of income. In turn, they observed an increase in gross product per capita in those regions where there was less financial provision before the experiment.

Similarly, Beck et al. (2007) considering a country-level perspective, measured the financial development in 72 countries, from 1960 to 2005, and related it with the levels of inequality and poverty. They used private credit statics to analyze the financial development, funding a positive relationship between this variable, the improvement of income distribution and the poverty alleviation.

Some other cross-country indicators were analyzed on The Vo et al. (2018) who studied the financial inclusion as an important key to reduce poverty and improve the macroeconomic stability, in 22 emerging and frontier economies from 2008 to 2015. They highlighted the literature debate regarding the link between financial inclusion and macroeconomic stability. On the one hand, the neglected 
growth of credit may culminate in financial crisis, but also the diversification of deposits in different segments may help overcome the crisis. They noticed that financial inclusion, measured as the growth rate in the number of bank branches over 100,000 account holders, improves financial stability under a certain threshold. Moreover, they also found that boosting financial inclusion is beneficial to the output growth and to contain inflation.

In a different framework, a usual practice between the academics in this area is to make an index of different measures of financial inclusion and create a ranking. A nominal paper of Sarma and País (2011) developed a methodology for a multidimensional index of financial inclusion, which was used in many works afterwards. For example, Park and Mercado (2015) designed an index, using this methodology, and measured the impact of financial inclusion over income distribution and poverty for Asian developing economies. They found significant results on the importance of income, demographic characteristics and governance or institutional quality on the effective promotion of financial inclusion.

This research analyzes the relationship between financial inclusion and some of the same macroeconomic variables used by these authors, but with an unexplored methodology in this area. The value of the study arises from the combination of different economies and variables to explain singular and grouping characteristics of countries and regions.

\section{Methodology}

The artificial neuronal networks (ANNs) are a powerful tool in data mining due to their ability to manage broad data fields and determining complex functional relationships. In ANNs there are two kinds of learning process: supervised or unsupervised. In the first case, there is an external agent that compares the output of the network with the desired output and modifies the weights in order to obtain a robust result. In the second case, the network itself fits the output using distance functions that measure the similarity between the input patterns of the system. The Self-organizing maps (SOM) have an unsupervised learning process that makes not necessary to define a priori the number of groups; they are determined considering similarities and differences of the elements that forms the input space.

The SOM are especially suited for clustering tasks, since this kind of networks gathers elements according to their homogeneity considering all the attributes or variables defined in the investigation. There has been an increase of their use in many fields for data mining, such as market segmentation, ecology or bioinformatics analysis (Lanzarini et al., 2017; Park et al., 2003) as well as for analysis of a great variety of economic and financial variables relations (SorrosalForradellas et al., 2017; Ecer, 2013; Terceño et al., 2013; Costea and Bleotu, 2012).

This variety in it use is because SOM were designed to convert highdimensional data, and greater number of samples, into more simple relationships of similarity graphs. Like in this work: the main macroeconomic fundamentals and financial inclusion indicators of a country in a year, for a total of 37 developed and developing countries, generating a total of 108 samples. In this sense, similar 
A Regional Kohonen Map of Financial Inclusion and Related Macroeconomic Variables

samples are closer in the map than the most dissimilar ones. For this reason, the SOM are appropriate in complex tasks of visualization and exploration of lineal and non-lineal relationships in high-dimensional datasets.

The process by which SOM obtains the feature map is as follows. First, input data are described in terms of vectors of $n$ components. In such way, a set of patterns $(P)$ is obtained as: $x^{p}=\left(x_{1}^{p}, x_{2}^{p}, \ldots, x_{n}^{p}\right)$ with $\mathrm{p}=1,2, \ldots n$, where $x_{i}^{p}$ represents the value of the $i$-th component for the pattern $p$. All the patterns are introduced into the system in a similar scale; if there are some differences, those variables must be normalized.

In each training step, the patterns are chosen linearly and compared with the weight vectors that form the rows in the matrix $W=\left(w_{k i}\right)_{k=1, \ldots m ; i=1, \ldots n}$, where $w_{k i}$ is the weight associated to the connection between the input neuron $i$ and the output neuron $k$. The winning neuron, called the Best-Matching Unit (BMU) is the neuron whose weight vector has the minimum distance with the pattern. Although different definitions of distance can be used, the most common one is the Euclidean distance. So, the winning unit $k^{*}$ satisfies:

$$
d_{k^{*}}^{p}=\min \left[d_{k}^{p}\right]_{k=1, \ldots m}=\min \left[\sqrt{\sum_{i=1}^{n}\left(x_{i}^{p}-w_{k i}\right)^{2}}\right]
$$

Once the winning neuron has been found, the weights associated to this neuron and also to its neighborhood area are updated. This is why the learning process is both competitive and cooperative. Is competitive because only one neuron wins due to the previous rule, but also cooperative because not only the BMU is modified but also its topological neighbors.

Two variants of the SOM training algorithm have been designed, the traditional sequential training and the batch training. In this work the second one was used since weights are calculated more efficiently with Matlab (Vesanto et al, 2000).

The new weights are obtained as a result of the following expression:

$$
w_{k i}(t+1)=w_{k i}(t)+\alpha(t)\left[x_{i}^{p}-w_{k^{*} i}(t)\right]
$$

where $\alpha(t)$ denotes the learning rate, which has a value between 0 and 1 and decreases monotonically with the number of iterations. The neighborhood area of the winning unit is formed by adjacent units in a rectangular or hexagonal area, and whose radius decreases with the number of iterations as well.

The $m$ number of neurons in the output layer is a key issue in SOM application; it depends on the amount of data being analyzed and the number of dimensions included. Although there is no deterministic theoretical principle to define the optimum map size, there is a tradeoff in relation to the map size: if it is too small, it might not explain some important differences within the data input. 
Conversely, if the map size increases, the tool loses explanatory power since it gets harder to identify similar patterns.

The SOM is trained with different map sizes, and the optimum size is selected based on a local minimum value for quantization error and topographic error. The QE is the average distance between each data vector and its BMU. Thus, this method only account for the relationship between the nodes and the neurons to which they are closest, but it does not reflect how the neurons are organized in relation to each other. For this purpose the topographic error is calculated, which represents the proportion of all data vectors for which the first and second BMUs are not adjacent, as a measure of topology preservation. This error value can be used as an indicator of the accuracy of the mapping in the preserving topology (Kohonen, 2001). Specifically, it evaluates the local discontinuities in the mapping (Breard, 2017). However, it should be noted that QE and TE gradually decrease as the map increases, so the optimum size will be based on local minimum values for $\mathrm{QE}$ and TE, somewhere between Vesanto et al. (2000)'s rule (an integer close to $5 \sqrt{ }$, where $\mathrm{n}$ is the number of training samples) and the same number of input data, since more neurons than data makes the tool unsuitable for clustering (Tian et al., 2014; Céréghino and Park, 2009; Park et al., 2003).

In the results section of the paper, the evolution of the QE and TE and the combination of both (Kaski and Lagus, 1996) are shown to present the optimum size of the map selected. Next, the map is analyzed.

\section{Data description}

The data used for the empirical analysis belongs to the International Monetary Fund (IMF) and The World Bank (WB). Two databases are considered: the general database that contains macroeconomics data and the Global Findex variables, which include updated indicators on access to and use of formal and informal financial services from their bases of 2011, 2014 and 2017.

The dimensions and the variables considered for each country are listed and explained in table 1.

Table 1. List of dimensions and variables

\begin{tabular}{|c|c|c|c|c|c|}
\hline Name & & Detail & Data Base & MAX & MIN \\
\hline \multicolumn{6}{|c|}{ FINANCIAL INCLUSION } \\
\hline $\begin{array}{l}\text { Financial } \\
\text { institution } \\
\text { account }\end{array}$ & $\mathrm{AC}$ & $\begin{array}{l}\text { The percentage of respondents who } \\
\text { report having an account (by themselves } \\
\text { or together with someone else) at a bank } \\
\text { or another type of financial institution. }\end{array}$ & $\begin{array}{l}\text { Global } \\
\text { Findex }\end{array}$ & 1.00 & 0.195 \\
\hline Debit Card & DBC & $\begin{array}{l}\text { The percentage of respondents who } \\
\text { report having a debit card. }\end{array}$ & $\begin{array}{l}\text { Global } \\
\text { Findex }\end{array}$ & 0.98 & 0.105 \\
\hline
\end{tabular}


A Regional Kohonen Map of Financial Inclusion and Related Macroeconomic Variables

\begin{tabular}{|c|c|c|c|c|c|}
\hline $\begin{array}{l}\text { Saved at a } \\
\text { financial } \\
\text { institution }\end{array}$ & SV & $\begin{array}{l}\text { The percentage of respondents who } \\
\text { report saving or setting aside any money } \\
\text { at a bank or another type of financial } \\
\text { institution in the past } 12 \text { months. }\end{array}$ & $\begin{array}{l}\text { Global } \\
\text { Findex }\end{array}$ & 0.79 & 0.038 \\
\hline Credit Card & $\mathrm{CRC}$ & $\begin{array}{l}\text { The percentage of respondents who } \\
\text { report having a credit card. }\end{array}$ & $\begin{array}{l}\text { Global } \\
\text { Findex }\end{array}$ & 0.70 & 0.005 \\
\hline $\begin{array}{l}\text { Borrowed at } \\
\text { a financial } \\
\text { institution }\end{array}$ & CRE & $\begin{array}{l}\text { The percentage of respondents who } \\
\text { report borrowing any money from a } \\
\text { bank or another type of financial } \\
\text { institution, or using a credit card, in the } \\
\text { past } 12 \text { months. }\end{array}$ & $\begin{array}{l}\text { Global } \\
\text { Findex }\end{array}$ & 0.35 & 0.018 \\
\hline $\begin{array}{l}\text { Electronic } \\
\text { Payments }\end{array}$ & ELP & $\begin{array}{l}\text { The percentage of respondents who used } \\
\text { electronic payments to make payments } \\
\text { on bills or to buy things using money } \\
\text { from their accounts, in the past } 12 \\
\text { months. }\end{array}$ & $\begin{array}{l}\text { Global } \\
\text { Findex }\end{array}$ & 0.98 & 0.006 \\
\hline $\begin{array}{l}\text { Financial } \\
\text { Institution } \\
\text { Access } \\
\text { Index }\end{array}$ & FIA & $\begin{array}{l}\text { It compiles data on bank branches per } \\
100,000 \text { adults and ATMs per } 100,000 \\
\text { adults }\end{array}$ & IMF & 1.00 & 0.164 \\
\hline \multicolumn{6}{|c|}{ MACROECONOMIC VARIABLES } \\
\hline $\begin{array}{l}\text { Gross } \\
\text { domestic } \\
\text { product per } \\
\text { capita }\end{array}$ & GDP & GDP per capita (constant 2010 US\$) & $\begin{array}{l}\text { WB } \\
\text { National } \\
\text { Accounts } \\
\text { Data }\end{array}$ & 91,451 & 2,024 \\
\hline Employment & EMPL & $\begin{array}{l}\text { Calculated as the rest of the percentage } \\
\text { of the labor force who is not } \\
\text { unemployed. The unemployment refers } \\
\text { to the share of the labor force that is } \\
\text { without work but available for and } \\
\text { seeking employment. }\end{array}$ & $\begin{array}{l}\text { OIT } \\
\text { (ILOSTAT) }\end{array}$ & 0.99 & 0.735 \\
\hline $\begin{array}{l}\text { Education } \\
\text { Index }\end{array}$ & EDU & $\begin{array}{l}\text { The education dimension is measured by } \\
\text { mean of years of schooling for adults } \\
\text { aged } 25 \text { years and older and expected } \\
\text { years of schooling for children of school } \\
\text { starting age. }\end{array}$ & $\begin{array}{l}\text { Human } \\
\text { Developme } \\
\text { nt Index }\end{array}$ & 0.94 & 0.598 \\
\hline $\begin{array}{l}\text { Exports of } \\
\text { goods and } \\
\text { services }\end{array}$ & EXP & $\begin{array}{l}\text { Exports of goods and services represent } \\
\text { the value of all goods and other market } \\
\text { services provided to the rest of the world } \\
\text { as a percentage of the GDP. }\end{array}$ & $\begin{array}{l}\text { WB } \\
\text { National } \\
\text { accounts, } \\
\text { OECD }\end{array}$ & 213 & 11.01 \\
\hline
\end{tabular}


All the variables presented must be between 0 and 1 in order to be able to use into the Kohonen map. The Global Findex variables are already in this dimension, as they are the percentage of the total answers sampled in the country. As well as the indexes used for financial institution access, education and employment. The only two variables that need to be normalized are GDP per capita and exportations as a percentage of the GDP, which in some cases is over $100 \%$, therefore these two variables are normalized by means of the range method on the same toolbox used to build the map.

The countries considered are those who presented all the data needed in the study for all the years selected. As the country-year data is included individually there is no need for all the three years data availability. But for those countries with two or three years, we would be able to observe the progressive process of their financial inclusion.

The countries included are 37, from three regions of the world under analysis, these are: 9 from Latin America, 19 from Europe and the last 9 correspond to the Asian tigers' countries group. The abbreviations are those used by the World Bank.

Table 2. List of countries by region

\begin{tabular}{|c|c|c|c|c|c|c|}
\hline \multicolumn{2}{|l|}{ Latin America } & \multicolumn{3}{|c|}{ Europe } & \multicolumn{2}{|r|}{ Asia } \\
\hline ARG Argentina & AUT & Austria & GRC & Greece & $\mathrm{CHN}$ & China \\
\hline BOL Bolivia & BEL & Belgium & HUN & Hungary & HKG & Hong Kong \\
\hline BRA Brazil & CZE & Czech Republic & IRL & Ireland & IDN & Indonesia \\
\hline CHL Chile & DEU & Germany & ITA & Italy & JPN & Japan \\
\hline COL Colombia & DNK & Denmark & NOR & Norway & KOR & Korea, Rep. \\
\hline MEX Mexico & ESP & Spain & NLD & Netherlands & MYS & Malaysia \\
\hline PER Peru & FIN & Finland & POL & Poland & PHL & Philippines \\
\hline PRY Paraguay & FRA & France & PRT & Portugal & SGP & Singapore \\
\hline URY Uruguay & GBR & United Kingdom & SWE & Sweden & THA & Thailand \\
\hline & & & $\mathrm{CHE}$ & Switzerland & & \\
\hline
\end{tabular}

There are missing data for some specific country-year data from the Global Findex Database, such as: Switzerland 2011, Paraguay 2014 and Norway 2011.

\section{Results}

4.1. Finding the best map.

Different models with a variable grid of neurons were made to compare and determine the optimal map size. To decide which model is best suited for the data, the quantification error media, the topological error and the combined error of both (Kaski and Lagus, 1996) are calculated and plotted in Graph $\mathrm{N}^{\circ} 1$, for squared 
A Regional Kohonen Map of Financial Inclusion and Related Macroeconomic Variables

grids of $i \times i$ sides, and for rectangular grids of $i$ x10 neurons, where $i$ varies between 3 and 15 .

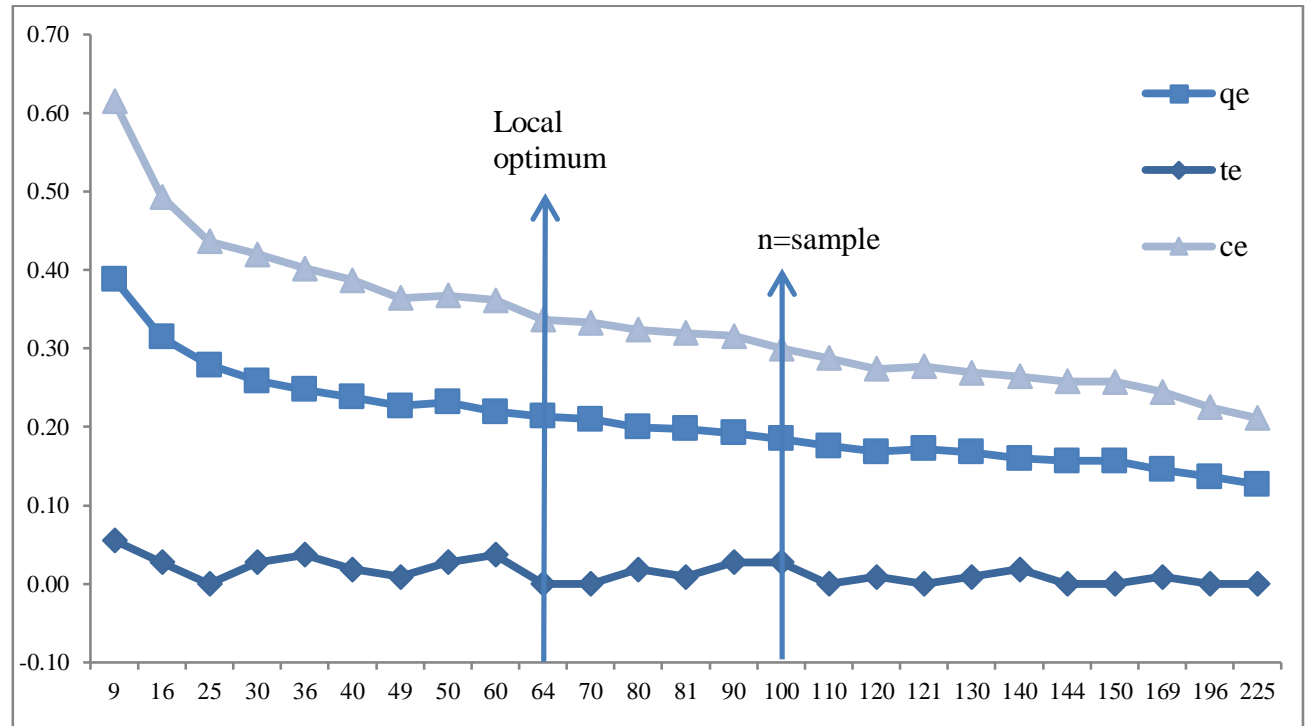

Graph 1. Quantification error, topological error and combined error of different grids

The quantization error is monotonously decreasing as the map size increases; the topological error oscillates to less than 0.10 or 0 , and the combined error copy parts of both errors. As is discussed in the methodology section there is a trade off on determining the optimal size of the map. When it is too small some important differences may not be observed, and the quantization error is very large. Conversely, a map too big loses explanatory power, since it gets more difficult to form clusters. Getting a map beyond the amount of data is not reasonable for the purpose of the tool. So between this ranges there is a local optimum in 64 neurons for our input data. Here the topological error is cero and the quantization error is 0.21 .

Then, once the optimal size of the map has been detected, the next section analyzes this map based on the distribution of the neurons, their weights and their grouping.

\subsection{Interpretation of the map}

Since the optimal size of the map was determined in 64 neurons, an $8 \times 8$ map grid is used to organize the patterns. In Figure 1 the U-Matrix is presented in the top left corner, and next to it, all the individual weight planes. 
The U-Matrix shows the unified distance matrix of a SOM. In this case of $8 \times 8$ sized map, the u-matrix is going to be a $15 \times 15$ vector. The first row, for example, will be:

$u(1) u(1,2) u(2) u(2,3) u(3) u(3,4) u(4) u(4,5) u(5) u(5,6) u(6) u(6,7) u(7) u(7,8) u(8)$

where $\mathrm{u}(\mathrm{i}, \mathrm{j})$ is the distance between map units $i$ and $j$ and $\mathrm{u}(\mathrm{k})$ is the mean of the surrounding values, e.g. $\mathrm{u}(3)=(\mathrm{u}(2,3)+\mathrm{u}(3,4)) / 2$. This is also what occurs with the columns. The graph does not provide a consistent interpretation of groups or distribution of the neurons since it is difficult to recognize which the distance and the mean distance are. Even though, it can be seen that there is only a small group of neurons distanced in the top left center, and some intermediate distance in the center, showing a separation from the top and the bottom neurons.

The weight planes show the distribution of the weight for each variable. The variable AC (Financial institution account), has a vertical distribution, neurons with lower weights are on the top left, and greater weights are in the bottom. Some intermediate weighted neurons are in the top right corner. Something similar happens for DED (Debit Cards) and SV (Savings in a Financial Institution), but the yellow area is shorter, since the levels of these variables are smaller. For CRC (Credit Card), GDP, ELP (Electronic Payments) and EDU (Education Index) variables, the distribution of weights is pretty similar, with a group of less weighted neurons on the top left, and the most weighted neurons on the bottom left. On the other side, in CRED (Credit on Financial Institutions), the group of less weighted neurons is on the top right. For the variables FIA (Financial Institution Access), EMP (Employment) and EXP (Exportations) a horizontal pattern of weights is identified, the first two are mirrored and Exportations is less variant, only a small group of neurons are above the $100 \%$ of GDP.
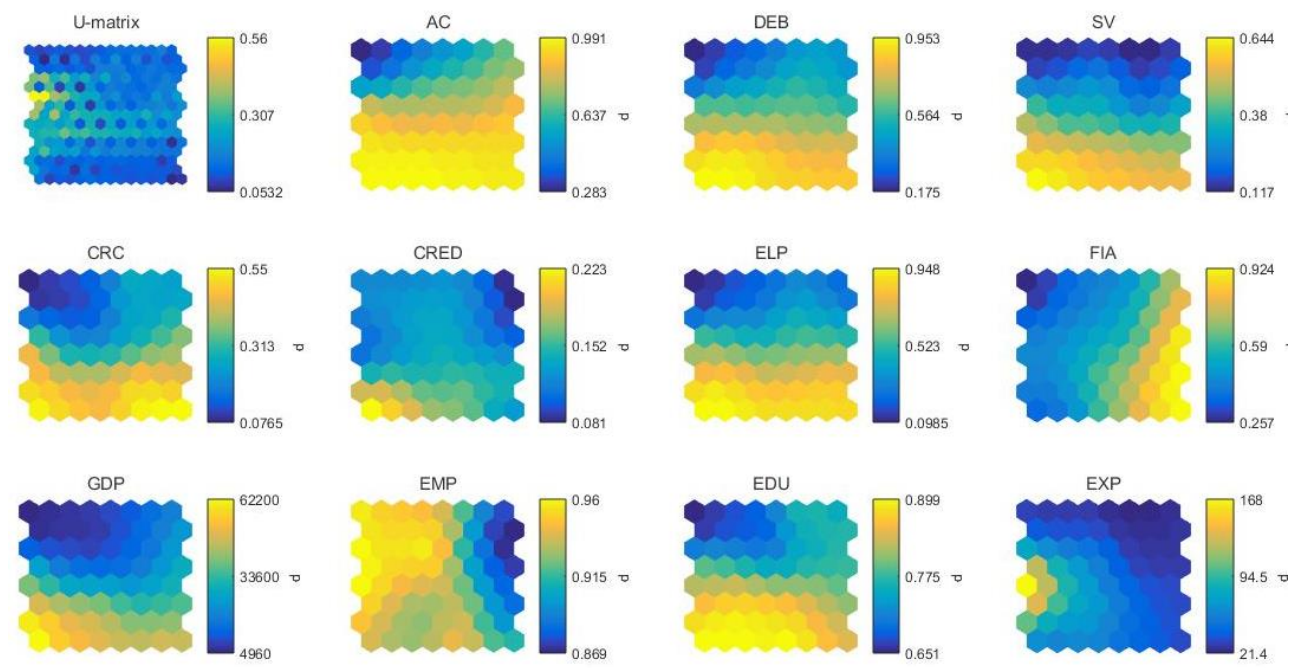

Figure 1. U-Matrix and weight planes 
A Regional Kohonen Map of Financial Inclusion and Related Macroeconomic Variables

As can be observed, some similar zones could be identified with similar patterns, but each variable has its own particularities with respect to its weights distribution. To be able to reduce the complexity on identifying groups of countries with similar situation and their evolution through time, a different way of visualization of the map is shown.

In the Figure $\mathrm{N}^{\mathrm{o}} 2$ the map grid is plotted with the labels of the countries in which the neuron won since its weights were close to the original vectors.

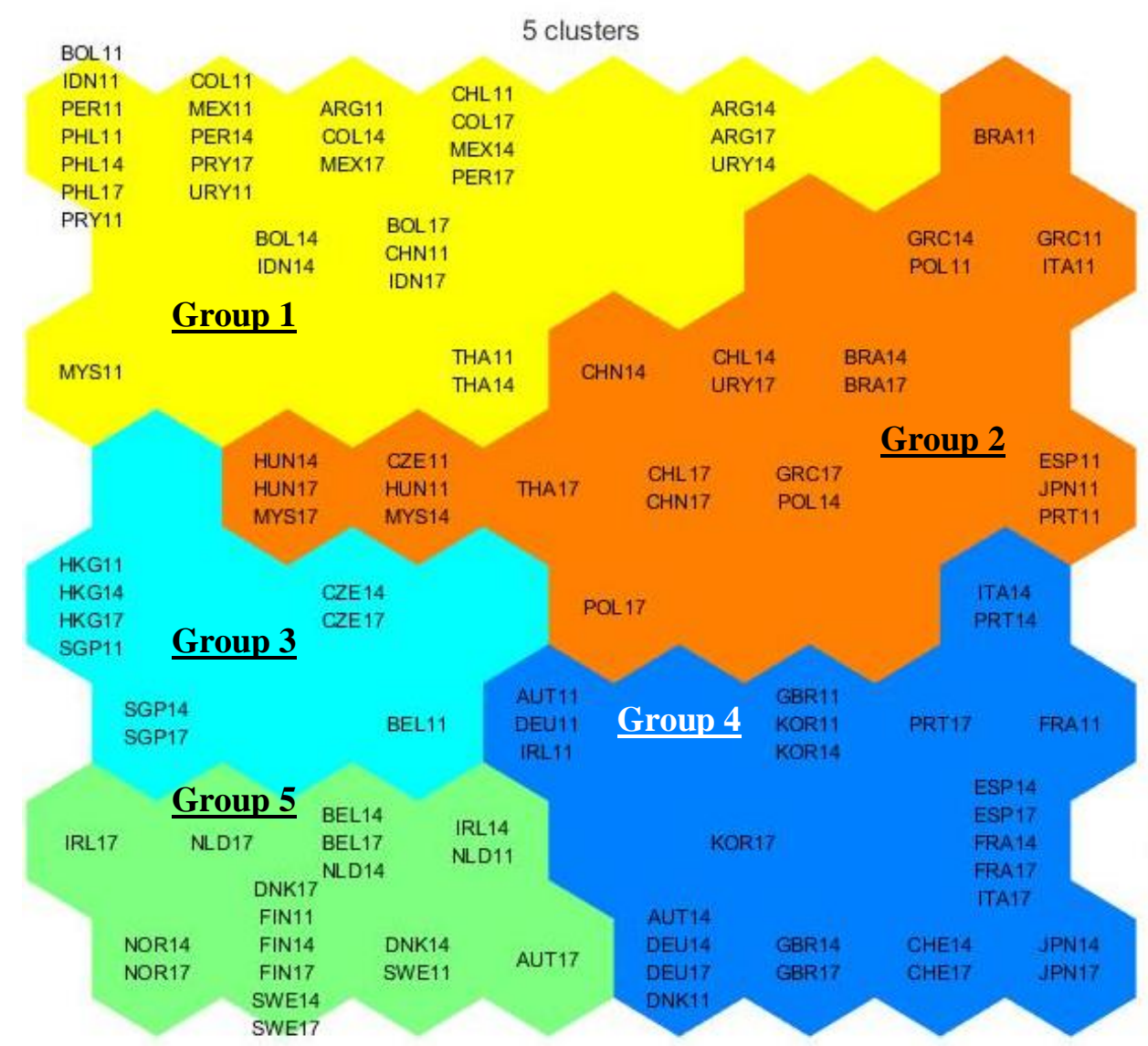

Figure 2: Map of countries in their BMU. 5 Clusters by k-means

As can be appreciated in Figure 2, Group 1 is made of most of the LatinAmerican countries, such as: Bolivia, Peru, Paraguay, Colombia, Mexico and Argentina in the three years of the study, also some Asian countries such as Indonesia and Philippines in the three years, and Thailand except for 2017. 
Malaysia, Chile and Uruguay during the year 2011 belonged to this group and then moved to Group 2.

The second group is the most heterogeneous. There are some Latin American countries like Brazil in the three years, Chile and Uruguay in 2014 and 2017, also Greece, Poland and Hungary in the three years, along with Italy, Spain, Portugal and Czech Republic only in 2011, going to Group 4 in 2014 and 2017. But also here are some Asian countries, such as China during the three years, Malaysia and Thailand for 2017, coming from group 1, and Japan only in 2011 moving to group 4 for the rest of the years of analysis.

The third group combines Hong Kong, Singapore, Czech Republic (which belonged to Group 2 for 2011) and Belgium for 2011, which goes to Group 5 for the years 2014 and 2017.

The fourth group comprises European countries such as Spain, Italy and Portugal, which along with Japan came from Group 2 for 2011. Denmark, Austria and Ireland were in this group for the year 2011, but then moved to Group 5. France, Germany, Korea, the United Kingdom and Switzerland belong to this group during the tree years of study. Moreover, Group 5 is composed in general by Scandinavian countries: Norway, Finland, Sweden and Netherlands, also Denmark and Ireland coming from Group 4, and Belgium for 2014 and 2017 coming from Group 3.

To understand why these groups have arisen and why these countries were moving from one to another group, Table 4 shows the average of each group for each variable used to build the map.

Table 4: Average indicators of the group of countries

\begin{tabular}{|c|c|c|c|c|c|c|}
\hline & 'AC' & 'DEB' & 'SV' & 'CRC' & 'CRED' & \\
\hline Group 1 & 0.50 & 0.35 & 0.18 & 0.15 & 0.12 & \\
\hline Group 2 & 0.77 & 0.56 & 0.26 & 0.27 & 0.12 & \\
\hline Group 3 & 0.89 & 0.74 & 0.46 & 0.37 & 0.13 & \\
\hline Group 4 & 0.95 & 0.81 & 0.49 & 0.48 & 0.15 & \\
\hline Group 5 & 0.98 & 0.92 & 0.60 & 0.49 & 0.19 & \\
\hline & 'ELP' & 'FIA' & 'GDP' & 'EMP' & 'EDU' & 'EXP' \\
\hline Group 1 & 0.25 & 0.40 & 9178.30 & 0.95 & 0.70 & 37.28 \\
\hline Group 2 & 0.46 & 0.64 & 19015.29 & 0.91 & 0.77 & 39.30 \\
\hline Group 3 & 0.68 & 0.47 & 35112.19 & 0.95 & 0.84 & 110.03 \\
\hline Group 4 & 0.81 & 0.79 & 39583.56 & 0.92 & 0.85 & 43.34 \\
\hline Group 5 & 0.90 & 0.46 & 53891.91 & 0.93 & 0.89 & 71.64 \\
\hline \multicolumn{7}{|c|}{ Davies-Bouldin index: 0.75} \\
\hline
\end{tabular}


A Regional Kohonen Map of Financial Inclusion and Related Macroeconomic Variables

Group 1 is the one with the lowest indicators. This group includes most of Latin American countries with Philippines, Indonesia and Malaysia (2011) and Thailand (2011 and 2014). These countries, denominated little Asian Dragons, such as Indonesia, Philippines, Malaysia and Thailand, are an extended, but more recent industrialized group than the original Asian Tigers, like Hong Kong, Singapore, South Korea and Taiwan (Park and Mercado, 2015).

Generally, this group shows very low indicators of financial inclusion; only half of the population has a bank account in these countries. Despite the fact that over the years their levels of financial inclusion have been improving, a backwardness remains in terms of financial inclusion, accessibility development (not compensated with electronic resources as in Group 5), low product per capita, education and exportations. The employment variable is high, but since the product is low, there is probably a different meaning in this case.

In Group 2 there are Latin-American countries which improved their levels of financial inclusion and their economy during the last years, like Chile and Uruguay, and Brazil, which belongs to this group for the three years. This group also comprises the European countries that were more affected by the 2008 financial and economic crisis, such as Italy, Spain, Portugal and Czech Republic only in 2011, changing their group for the years 2014 and 2017. Greece, Poland and Hungary remained in this group for the three years. The employment index is a bit small, but the GDP per capita is twice than that of group one and the percentage of exportation to GDP is also bigger. The financial access index is greater than that of group one, as well as electronic payments index.

In Group 3 there are Asian countries gathered such as Hong Kong, Singapore, Czech Republic and Belgium for 2011 going to Group 5 for the other years. This group is distinguished because it presents the highest export indicator over GDP. It has better levels of financial inclusion and GDP per capita than the previous two groups. The average of employment index is the same as the Group 1, but this group shows a higher education index.

For Group 4 the situation of financial inclusion and macroeconomics are good, but still not as good as the Group 5. This contains European countries such as Spain, Italy and Portugal (for 2014 and 2017). Denmark, Austria and Ireland belonged to this group for 2011, but then moved to Group 5, and France, Germany, the United Kingdom and Switzerland are in this group for the tree years. Asian countries, like Korea and Japan for 2014 and 2017, also belong here. This group has the highest index of financial access as the combination of Automated Teller Machines and bank subsidiaries per 100,000 habitants, followed by Group 2 .

Finally, Group 5 has the best indicators of the whole sample of countries. It shows high levels of financial inclusion and solid economies, the greatest GDP per capita of all groups, a high index of employment, education and exportations. It has a reduced financial institution accessibility, which could be explained by the fact that, in countries with smaller territory, the population is located in urban areas, 
where there is no need for more investment in expanding the net of bank branches or ATMs. Besides, the index of electronic payments is the highest in the sample, so if the population uses the electronic resources, they reduce their demand of services on ATMs and Bank branches. In turn, credit and credit card levels are high but still moderated.

Summarizing, the map classified the countries into five groups. On the one hand, we find a group of low rates of financial inclusion and macroeconomic performance (Group 1). On the other hand, we detect a group of high financial inclusion and improved macroeconomic situation (Group 5). There are three intermediate groups, which present different levels of some variables, such as: the usage of credit, GDP levels, and exportation index.

In terms of geographical belonging, the European countries were divided in three subgroups; the first one is formed by northwest countries, the second one by countries of the west and center of Europe, and the third one of southerners or those more affected by the international crisis. Many of them showed an improvement in terms of switching groups, like Spain, Italy and Portugal from Group 2 to 4, or like Denmark, Austria and Ireland from Group 4 to 5, also. Belgium moved from Group 3 to 5 too. And some remained in Group 2 showing low indicators, such as Greece, Poland and Hungary.

Asian countries are more scattered. Hong Kong and Singapore represent Group 3 with the highest levels of export as GDP. Korea and Japan are in Group 4, together with other European countries with good performance, and also with Malaysia and Thailand for 2017. But Indonesia, Philippines and Malaysia (2011) and Thailand (2011 and 2014) are in the first group of lower indicators.

Finally, Latin American countries are mostly in the first group, with low indicators of financial inclusion and macroeconomic variables. Argentina, México, Peru, Bolivia and Colombia remained in this group for the three years. Some exceptions for the region were Brazil belonging to Group 2 during the three years, and Chile and Uruguay which distanced from Group 1 on 2014 and 2017, moving to Group 2.

\section{Conclusions}

In this work, a set of countries from different regions were analyzed in order to detect similarities in their levels of financial inclusion and evolution of some economics variables. In others words, we detected that the financial inclusion is in accordance with the macroeconomics variables selected.

In order to achieve the illustration of the big amount of data and variables gathered, the self-organizing maps of Kohonen were used. This is a type of neural network with unsupervised learning that creates a net of neurons that are representative of the topology of the input data.

Different sizes and error measures were calculated in order to assure that the final map was the most suitable for the data input. And, finally, a k-means algorithm was used to determine five groups of neurons that were close and distanced from the others. 
A Regional Kohonen Map of Financial Inclusion and Related Macroeconomic Variables

In turn, a group of high financial inclusion with great product per capita, employment and education index was found. It also has high levels of electronic payments indicator that compensate -in theory- the reduced index of financial access. This group comprises most of the wealthy northern European countries.

On the other hand, a group of less than one-sixth of the product per capita in average was identified, of most of the Latin American countries, along with Indonesia and Philippines. This group has low levels of financial inclusion, of electronic payments and also financial access index, which means that in these cases, these variables do not compensate each other. The employment is high, but the GDP per capita and the education and exportation indexes are low.

Some intermediate groups show moderate levels of financial inclusion and their economy are in a more advanced transition, like Brazil, Chile and Uruguay. They improved their levels in 2014 and 2017 and changed into a more intermediate group. With respect to European countries, Italy, Spain and Portugal were in a group of low indicators, together with Greece, Poland and Hungary, but they improved their situation and moved to the next group. The cases of Belgium, Denmark, Austria and Ireland joined the group with the best indicators.

Therefore, in terms of geography, the European and the Latin-American countries form part of common groups and share similar trajectories, but the Asian ones are more different between them. Hong Kong and Singapore represent a group with the highest levels of export as GDP. Korea and Japan are in an intermediate group and also with Malaysia and Thailand for 2017. But Indonesia, Philippines and Malaysia (2011) and Thailand (2011 and 2014) remained in the group of lowest indicators.

For future research, it would be interesting to analyze the evolution of each group over the years, to identify the events or policies that could have affected an individual country, their macroeconomic variables, or the financial inclusion variables. Nevertheless, it is important to highlight the need to implement policies oriented to financial education and the development of financial infrastructure in order to improve financial inclusion.

ACKNOWLEDGEMENTS

This work is in the framework of the projects named "Social inclusion: innovations and public policies. $A$ regional analysis" (PUE: $22920160100069 \mathrm{CO}$ ) and "Analysis of Microfinance in Argentina. Case of study of the Southwest Buenos Aires province” (Res. CSU 329/17).

\section{REFERENCES}

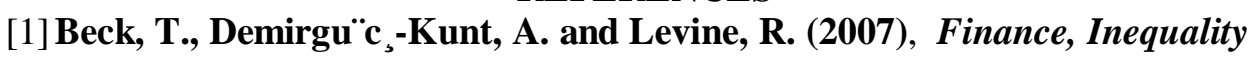
and the Poor. Journal of Economic Growth, 12, pp.27-49; 
[2] Breard, G. T. (2017), Evaluating Self-Organizing Map Quality Measures as Convergence Criteria; Open Access Master's Theses, Paper 1033. Available at: http://digitalcommons.uri.edu/theses/1033 (accessed 04 February 2020);

[3] Bruhn, M., Love, I. (2014), The Real Impact of Improved Access to Finance: Evidence from Mexico. The Journal of Finance, 69(3), pp.1347-1376;

[4] Céréghino, R., Park, Y.S. (2009), Review of the Self-Organizing Map (SOM) Approach in Water Resources: Commentary; Environmental Modelling \& Software, vol. 23, Issue 7, pp. 835-845;

[5] Čihák, M., Demirgüç-Kunt, A., Feyen, E., Levine, R. (2012), Benchmarking Financial Systems around the World; Working Paper No. 6175, World Bank Policy Research, Washington DC, 2012;

[6] Collins, D. Morduch, J., Rutherford, S., Ruthven, O. (2009), Portfolios of the Poor: How the World's Poor Live on \$2 a Day; Princeton University Press, United States;

[7] Costea, A., Bleotu, V. (2012), A New Fuzzy Clustering Algorithm for Evaluating the Performance of Non-Banking Financial Institutions in Romania. Economic Computation and Economic Cybernetics Studies and Research; ASE Publishing; 46(4), pp. 179-199;

[8] De Olloqui, F. Andrade, G., Herrera, D. (2015), Inclusión financiera en América Latina y el Caribe: coyuntura actual y desafios para los próximos años; Working Paper IDB-DP-385. Inter-American Development Bank, June 2015;

[9] Demirguc-Kunt A., Klapper, L. (2013), Measuring Financial Inclusion: Explaining Variation in Use of Financial Services across and within Countries; Brookings Papers on Economic Activity, vol. 44, issue 1 (Spring), pp. 279-340; [10] Ecer, F. (2013), Artificial Neural Networks in Predicting Financial Performance: An Application for Turkey's Top 500 Companies; Economic Computation and Economic Cybernetics Studies and Research; ASE Publishing; 47(2), pp.103-114;

[11] Ezenwakwelu, G. C. (2018), Effects of Financial Inclusion on Selected Macroeconomic Variables In Nigeria; Global Journal of Applied, Management and Social Sciences (GOJAMSS), vol. 15, June, pp. 259 - 271;

[12] Kaski, S., Lagus, K. (1996), Comparing Self-Organizing Maps. In Von der Malsburg C., Von Seelen W., Vorbruggen J. C. and Sendho (Eds.), Proceedings of ICANN96, International Conference on Artificial Neural Networks, Lecture Notes in Computer Science, B. Springer, Berlin, 1996, vol. 1112, pp. 809-814;

[13] Kohonen, T. (2001), Self-Organizing Maps; 3rd. ed., Springer, Berlin; [14] Lanzarini, L. C., Monte, A. V., Bariviera, A. F., Santana, P. J. (2017), Simplifying Credit Scoring Rules Using LVQ+PSO; Kybernetes, Vol. 46, No. 1, pp. 8-16;

[15] Marconi, R. (2014), El milagro de inclusión financiera. La industria microfinanciera de Bolivia (1990-2013). La Paz: HIVOS; Fundación PIEB; Academia Boliviana de Ciencias Económicas; 
A Regional Kohonen Map of Financial Inclusion and Related Macroeconomic Variables

[16] Martínez Pería, M. S. (2014), Financial Inclusion in Latin America and the Caribbean; En Didier T. and Schmukler S. L., Emerging Issues in Financial Development, Washington D.C. The World Bank, pp. 91-127;

[17] Park, C. Y.,Mercado, R. J. (2015), Financial Inclusion, Poverty, and Income Inequality in Developing Asia; Working paper No. 426, Asian Development Bank Economics, Philippines, January;

[18] Park, Y. S., Céréghino, R., Compin, A., Lek, S. (2003), Applications of Artificial Neural Networks for Patterning and Predicting Aquatic Insect Species Richness in Running Waters. Ecological modelling, 160(3), 265-280;

[19] Sahay, R., Čihák, M., N'Diaye, P., Barajas, A., Srobona, M., Kyobe, A., Yen Nian, M.,Reza Yousefi, S. (2015), Financial Inclusion: Can It Meet Multiple Macroeconomic Goals?. Working paper SDN/15/17, International Monetary Fund, September 2015;

[20] Sarma, M., Pais, J. (2011), Financial Inclusion and Development; Journal of International Development, 23(5), pp. 613-628;

[21] Singh, N. (2017), Financial Inclusion: Concepts, Issues and Policies for India; Working paper I-35406-INC-1, International Growth Center, Available at: http://www.theigc.org/wp-content/uploads/2017/05/Singh-2017-Synthesispaper.pdf (accessed 04 February 2020);

[22] Sorrosal-Forradellas, M.T., Martinez, L.B., Terceño, A. (2017), Are European Sovereign Bond Spreads in Concordance with Macroeconomic Variables Evolution?; Kybernetes, Vol. 46 Iss 1, pp. 85 - 101;

[23] Terceño, A., Martinez, L. B., Sorrosal-Forradellas, M. T. (2013), Do Sovereign Bond Spreads in EU Converge? An Analysis through Self-Organizing Maps; Economic Computation \& Economic Cybernetics Studies \& Research; ASE Publishing: Vol. 47, No. 4;

[24] The Vo, A., Thi-Hong Van, L., Hong Vo, D., McAleer, M. (2018), Financial Inclusion and Macroeconomic Stability in Emerging and Frontier Markets; Working Paper No. 1901; Universidad Complutense de Madrid, 2018; [25] Tian, J., Azarian, M. H., Pecht, M. (2014); Anomaly Detection Using SelfOrganizing Maps-based k-Nearest Neighbor Algorithm; In Bregon, A. and Daigle, M.J., Proceedings of the European Conference of the Prognostics and Health Management Society, Nantes, France, July 2014, pp. 110-119;

[26] Vesanto, J., Himberg, J., Alhoniemi, E., Parhankangas J. (2000), SOM Toolbox for Matlab 5; Technical Report A57, Neural Networks Research Centre, Helsinki University of Technology, Helsinki, Finland;

[27] World Bank (2014), Global Financial Development Report 2014: Financial Inclusion. Washington, DC: World Bank. Available at: http://documents.worldbank.org/curated/en/225251468330270218/Global financial-development-report-2014-financial-inclusion (accessed 04 February 2020). 